\title{
PRIMARY TUBERCULOSIS OF PENIS: A RARE CASE REPORT
}

\author{
Imdad Ali N ${ }^{1}$, Ramesh K. R², Shivashankarappa $\mathrm{M}^{3}$, Ravishankar T. H. S4
}

\section{HOW TO CITE THIS ARTICLE:}

Imdad Ali N, Ramesh K. R, Shivashankarappa M, Ravishankar T. H. S. "Primary Tuberculosis of Penis: A Rare Case Report". Journal of Evolution of Medical and Dental Sciences 2015; Vol. 4, Issue 41, May 21;

Page: 7237-7240, DOI: 10.14260/jemds/2015/1050

\begin{abstract}
Primary tuberculosis of penis is very rare and we present a case report of it presenting as ulcer over the glans. Biopsy and histopathological examination confirmed the diagnosis and patient responded well for antitubercular treatment. Sexual partner evaluation turned out to be having genital tuberculosis and possibility of spread through sexual contact is strongly considered. Rarity of the clinical case is emphasized here.
\end{abstract}

KEYWORDS: Penis, Ulcer, Primary tuberculosis.

INTRODUCTION: Tuberculosis of the penis in adults is very rare and it presents usually as Primary tuberculosis of the penis presenting as an ulcer over glans or prepuce. It also can be secondary to genitourinary tuberculosis or haematogenous spread from pulmonary tuberculosis or other organs. In literature only 139 cases up to 1979 are reported. ${ }^{1}$ It starts as a chronic process, by the formation of infected granulation tissue, which gradually infiltrates the glanular and cavernous tissues and may invade the whole thickness of the penis. ${ }^{2}$

In the past ritual circumcision was a frequent cause in developed countries. At present primary tuberculosis of the penis is extremely rare in developed countries where infantile ritual circumcision is still practiced, but it is occasionally seen in underdeveloped areas. ${ }^{3}$ We report a rare case of primary tuberculosis of penis in 30 years old, presenting as an ulcer over the glans and histopathologically turned out to be tuberculosis.

CASE REPORT: 30 years old married person presented to us with history of painless ulcer over glans since 3 months. Before coming to us he was treated by various practitioners and details of medications were not available. He denied any extra marital sexual contact. There was no family or personal history of tuberculosis .On physical examination he was found to have an oval shaped ulcer of about $1 \mathrm{~cm}$ diameter over the glans penis with undermined edges and non-indurated base (Fig. 1) with rest of external genitalia being normal. There was no enlargement of regional lymph nodes

Patient was evaluated with routine blood and urine examinations which were within the normal limits.Hb-14.4gms, TC-8500/cubic mm, DC (N-69, L-25, E-3, M-2, B-1), RBS-100mg/dl, serum creatinine- $0.5 \mathrm{mg} / \mathrm{dl}$. Serological tests for Venereal Disease Research Laboratory (VDRL), Trepanema pallidum haem agglutination (TPHA), Fluorescent trepanemal antibody (FTA abs), for Chlamydia trachomatis (Indirect immunoflourescence (IIF) were negative. Dark field microscopy for Trepanema pallidum, swab-cultures for Haemophilus ducreyi and other aerobic bacteria and fungi gave negative results. Edge biopsy of ulcer revealed chronic granulomatous lesion with giant Langerhans type of cells consistent with tuberculosis (Fig. 2). Sputum for AFB and culture, urine for culture, chest x-ray and abdominal sonography showed normal results.

Patient was started with revised national tuberculosis control programme (RNTCP) extra pulmonary treatment with alternate day oral administration of INH, rifampicin, and pyrazinamide for 
2 months followed by only INH and rifampicin daily for another 4 months. After 2 months of treatment ulcer healed and after completion of ATT lesion was completely disappeared (Fig. 3). As a part of evaluation patient wife was referred to gynaecologist and on evaluation found to have genital tuberculosis and treated accordingly. Most probable route of spread here is sexual contact from wife who was asymptomatic.

DISCUSSION: Though tuberculosis can affect any organ, tuberculosis of penis is a rare disease. Tuberculosis of penis usually is primary which spreads during ritual and nonritual circumcision, coitus, and contaminated cloths. ${ }^{3}$ Less of the times it is secondary due to spread from genitourinary tuberculosis and haematogenus spread from lungs and other organs. ${ }^{2}$ In the literature only 139 cases till 1979 and few more cases were reported since then. ${ }^{4}$ Primary tuberculosis of penis presents as an ulcer over glans, corona or prepuce and also as painless hard nodule. In one reported case it also presented as gangrene of penile skin. ${ }^{7}$ In order to establish the diagnosis it needs to be differentiated clinically and by laboratory studies from chancre, chancroid and more important from malignant ulcer of penis by biopsy. ${ }^{5}$ Primary tubercular ulcer from secondary penile tuberculosis should be differentiated by chest X-ray, ultrasound abdomen, IVP, urine culture, and urine culture for mycobacterium tuberculosis. ${ }^{6}$ In this case the presentation was as a single painless ulcer over the glans of 3 months duration; histopathology confirmed the diagnosis and prompt response to antitubercular treatment further supported the diagnosis. Sexual partner evaluation revealed genital tuberculosis and indirectly established the route of spread in this particular case.

\section{REFERENCES:}

1. Lewis EL. Tuberculosis of the penis: a report of 5 new complete review of the literature. J Urol 1946; 56: 737-745.

2. Cambell walsh, urology, tenth edition, vol. 1, page 470.

3. Annobil SH, al-Hilfi A, Kazi T. Primary tuberculosis of the penis in an infant. Tubercle 1990; 71: 229-230.

4. Ramesh V, Vasanthi R. Tuberculous cavemositis of the penis, case report. Genitour Med 1989; 65: 58-59.

5. Sekhon GS, Lal MM, Dhall JE. Tuberculosis of penis. J Indian Med Assoc 1971; 56: 316-8.

6. Guy M, Eisenkraft S, Elivaz A. Primary tuberculosis of the glans penis. Harefuah 1993; 125(9)260-1, 328.

7. Rangnekar N P, Sanzgiri M D, Ali N I, Pathak H R. Tuberculous gangrene of the penis. Indian J Urol 2000; 17: 51-2. 


\section{CASE REPORT}

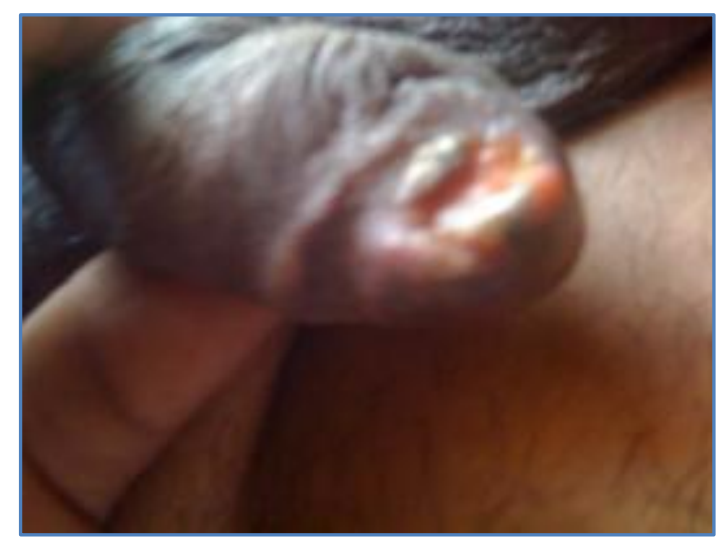

Fig. 1: Penile ulcer before ATT

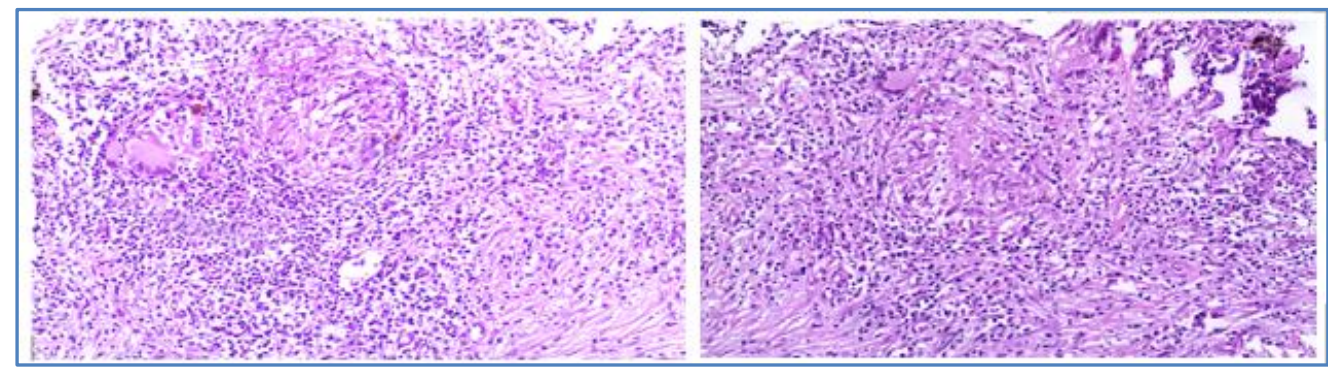

Fig. 2: Microscopic picture of penile ulcer biopsy in low and high power fields

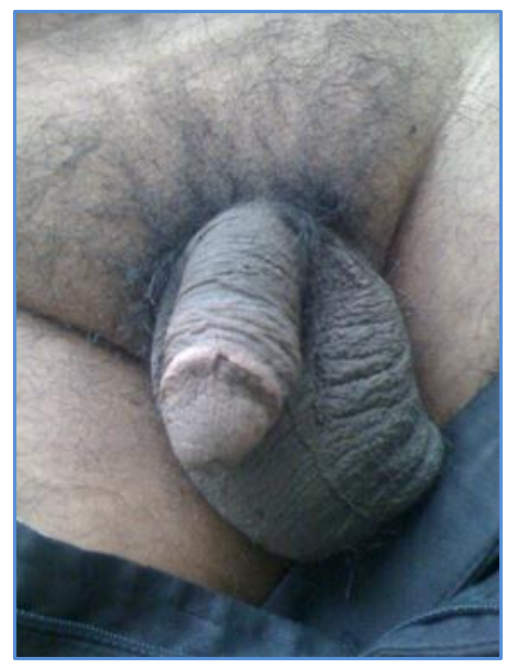

Fig. 3: healed penile ulcer after ATT 


\section{AUTHORS:}

1. Imdad Ali N.

2. Ramesh K. R.

3. Shivashankarappa M.

4. Ravishankar T. H. S.

\section{PARTICULARS OF CONTRIBUTORS:}

1. Professor \& HOD, Department of Urology, VIMS, Bellary.

2. Resident, Department of Urology, VIMS, Bellary.

3. Associate Professor, Department of Urology, VIMS, Bellary.

FINANCIAL OR OTHER

COMPETING INTERESTS: None
4. Assistant Professor, Department of Urology, VIMS, Bellary.

\section{NAME ADDRESS EMAIL ID OF THE} CORRESPONDING AUTHOR:

Dr. Imdad Ali N, Professor \& HOD, Department of Urology, Vijaya Nagara Institute of Medical Sciences, Bellary-582104, Karnataka.

E-mail: drimdadali@gmail.com

Date of Submission: 28/04/2015.

Date of Peer Review: 29/04/2015.

Date of Acceptance: 13/05/2015.

Date of Publishing: 21/05/2015. 